\title{
Iogurte probiótico produzido com leite de cabra suplementado com Bifidobacterium spp.
}

\author{
[Probiotic yogurt produced with goat milk supplemented with Bifidobacterium spp.] \\ V. Mazochi ${ }^{1}$, F.E. Matos Júnior ${ }^{2}$, C.H. Val ${ }^{2}$, D.N. Diniz ${ }^{2}$, A.F. Resende ${ }^{2}$, \\ J.R. Nicoli ${ }^{3}$, A.M. Silva ${ }^{4}$ \\ ${ }^{1}$ Aluna de mestrado - Uni-BH - Belo Horizonte, MG \\ ${ }^{2}$ Aluno de graduação - Uni-BH - Belo Horizonte, MG \\ ${ }^{3}$ Universidade Federal de Minas Gerais - Belo Horizonte, MG \\ ${ }^{4}$ Universidade Federal de São João del-Rei - Campus Sete Lagoas, MG
}

\begin{abstract}
RESUMO
Avaliaram-se iogurtes de leite de cabra contendo ou não Bifidobacterium longum, $B$. breve, $B$. pseudolongum ou B. bifidum, adicionados ou não de aroma de morango. Os dados obtidos nas análises higiênico-sanitárias e físico-químicas foram dentro dos valores exigidos pela legislação brasileira; apenas o valor encontrado para lactose esteve abaixo do recomendado. Quanto às bactérias do iogurte, não houve diferença na contagem de Streptococcus salivarius subsp. thermophilus durante a estocagem, e não foi detectado Lactobacillus delbrueckii subsp. bulgaricus nas diluições utilizadas. A enumeração de Bifidobacterium spp. manteve-se entre $10^{6}$ e $10^{8} \mathrm{UFC} / \mathrm{mL}$ e não diferiu entre as espécies ao longo do tempo. Considerando-se a adição ou não de aroma, a análise das variáveis tempo e aroma não mostrou diferença estatística. A contagem entre os Bifidobacterium spp. demonstrou que nenhum microrganismo apresentou um comportamento superior a outro. Na análise sensorial, as amostras de iogurtes adicionados ou não de Bifidobacterium spp. e adicionados de aroma de morango não apresentaram diferenças entre si. O estudo mostrou ser possível a elaboração de iogurte de leite de cabra adicionado de Bifidobacterium spp. e de aroma de morango com qualidade assegurada, potencial para uso probiótico e boa aceitação pelo consumidor.
\end{abstract}

Palavras-chave: leite de cabra, iogurte, probiótico, Bifidobacterium, alimento funcional

\begin{abstract}
Goat milk yogurt with or without Bifidobacterium longum, B. breve, B. pseudolongum, or B. bifidum, and supplemented or not with strawberry aroma were evaluated. Data obtained from hygienic-sanitary and physicochemical analyses were within the values recommended by the Brazilian legislation, except for lactose contents, which were lower than the recommended. In relation to the yogurt bacteria, there was no difference in the counts of Streptococcus salivarius subsp. thermophilus during the storage, and Lactobacillus delbrueckii subsp. bulgaricus was not detected. The counts of Bifidobacterium spp. ranged from $10^{6}$ to $10^{8} \mathrm{CFU} / \mathrm{mL}$, without difference between the species along the time. Considering the addition of flavor or not, the analysis of aroma and time variables showed no statistical difference. The counts of Bifidobacterium spp. demonstrated that none showed a superior value. For the hedonic scale test, there was no difference between yogurts supplemented or not with Bifidobacterium spp., and added or not with strawberry aroma. The study showed to be possible the elaboration of goat milk yogurt supplemented with Bifidobacterium spp. and strawberry aroma, presenting safety, potential for probiotic use, and good acceptability by consumers.
\end{abstract}

Keywords: goat milk, yogurt, probiotics, Bifidobacterium, functional food

Recebido em 20 de setembro de 2009

Aceito em 15 de outubro de 2010

E-mail: vmazochi@yahoo.com.br 


\section{INTRODUÇÃO}

O leite caprino apresenta elevado valor biológico e qualidades nutricionais que diferem do leite bovino. Sua maior digestibilidade, alcalinidade distinta e características dietéticas fazem com que seja altamente recomendado para a alimentação infantil e de adultos sensíveis ou alérgicos ao leite de vaca (Costa, 2003). No Brasil, o leite de cabra vem conquistando mercado, tanto na forma de leite pasteurizado e congelado como de leite em pó e derivados, sendo o iogurte um produto de grande aceitação (Cordeiro, 1998).

Dentre os leites fermentados, o iogurte destacase com predominância no mercado mundial, constituindo uma rica fonte de proteínas, cálcio, fósforo, vitaminas e carboidratos (Ferreira et al., 2001). Alimentos funcionais são caracterizados por oferecer vários benefícios à saúde, além do valor nutritivo inerente à sua composição química (Moraes e Colla, 2006). Fabian et al. (2008) ressaltaram a ação dos microrganismos envolvidos no processo fermentativo do leite e mostraram sua atuação benéfica no iogurte, enquanto Lourens-Hattingh e Viljoen (2001) relataram seu uso no tratamento de infecções intestinais. No Brasil, o interesse por produtos lácteos fermentados tem aumentado, e alguns iogurtes suplementados com bactérias probióticas têm sido desenvolvidos (Ribeiro e Ribeiro, 2001).

Os probióticos podem agir por antagonismo direto contra espécies patogênicas pela produção de ácidos orgânicos, peróxido de hidrogênio, antibióticos e bacteriocinas, por competição por nutrientes e sítios de adesão em mucosas, por modulação do sistema imune do hospedeiro e por produção de enzimas que melhoram a digestão dos alimentos ou detoxificam os metabólitos nefastos da microbiota (Plant e Conway, 2001). São características importantes para a seleção de um probiótico: a capacidade de permanecer viável e manter a sua atividade no ecossistema gastrointestinal do hospedeiro, a capacidade de se manter viável durante o processamento e a estocagem do produto e ser completamente seguro para o consumo humano (Lee e Salminen, 1995; Grosso e Fávaro-Trindade, 2004). Cepas que exercem seu efeito benéfico nos intestinos devem ser capazes de tolerar os diversos fatores bióticos e abióticos interferentes, como fatores físico-químicos: pH, potencial de oxidorredução, secreção biliar, disponibilidade de nutrientes e atividade imunológica local (O’Sullivan et al., 1992).

Este trabalho teve os objetivos de avaliar as características microbiológicas, físico-químicas e sensoriais na matéria-prima e no produto, bem como desenvolver iogurtes de leite de cabra contendo ou não $B$. longum, $B$. breve, $B$. pseudolongum ou B. bifidum, adicionados ou não de aroma de morango.

\section{MATERIAL E MÉTODOS}

O leite de cabra cru (Contagem/MG) foi homogeneizado e submetido a análises físicoquímicas de $\mathrm{pH}$, acidez titulável e densidade segundo AOAC (Official..., 1997) e análise microbiológica de contagem padrão em placa (Brasil, 2001). A seguir, o leite foi tratado à temperatura de $93^{\circ} \mathrm{C}$ e amostras foram retiradas para as análises físico-químicas e microbiológicas: $\mathrm{pH}$, acidez titulável, densidade, percentual de proteína, gordura, lactose, cinzas e extrato seco total e desengordurado, contagem de microrganismos mesófilos, número mais provável para coliformes a $30 / 35^{\circ} \mathrm{C}$ e $45^{\circ} \mathrm{C}$ e pesquisa de Salmonella (Brasil, 2001).

O cultivo lácteo comercial YF-L812 (Christian Hansen Lab. - Horsholm, Dinamarca) foi utilizado para a cultura mãe por semeadura direta em $1 \mathrm{~L}$ de leite de cabra previamente fervido e resfriado até $43^{\circ} \mathrm{C}$. A cultura foi, então, guardada em porções de $20 \mathrm{~mL}$, que foram congeladas em freezer convencional.

As cepas de Bifidobacterium spp. cedidas pelo Prof. Jacques R. Nicoli (Departamento de Microbiologia/UFMG) foram isoladas de fezes de crianças sadias e identificadas por PCRMultiplex. Após duas reativações em caldo MRS (Oxoid - Basingstoke, Inglaterra), as culturas de Bifidobacterium spp. foram centrifugadas por $10 \mathrm{~min}$ a $5.000 \mathrm{rpm}$, lavadas com água peptonada e ajustadas na concentração de $10^{10} \mathrm{UFC} / \mathrm{mL}$.

Após o tratamento térmico a $93^{\circ} \mathrm{C}$, o leite resfriado a $43^{\circ} \mathrm{C}$ foi adicionado à cultura iniciadora $(2 \% \mathrm{v} / \mathrm{v})$, homogeneizado e incubado a $43^{\circ} \mathrm{C}$ por três horas para produção do iogurte. Após este período, o produto foi mantido na geladeira por 24h. Em seguida, foram 
acrescentados $0,1 \%$ de sacarose e $0,5 \%$ de aroma de morango (Tecnomilk - São Paulo) e, antes da sua distribuição em embalagens de $200 \mathrm{~mL}, 1 \mathrm{~mL}$ de cada cultura de Bifidobacterium spp. foi acrescentado. Depois de embalados, os iogurtes foram armazenados sob refrigeração por 40 dias.

A contagem de Streptococcus salivarius subsp. thermophilus nos iogurtes foi realizada por semeadura spread plate no meio M17 (Difco, Le Pont de Claix, França) após incubação a $37^{\circ} \mathrm{C}$ por 48h (Brasil, 2000a). A contagem de Lactobacillus delbrueckii subsp. bulgaricus foi realizada por semeadura pour plate no meio MRS (Oxoid) utilizando-se as mesmas condições de incubação do estreptococo. As contagens foram feitas um, 15 e 40 dias após a produção do iogurte, assim como as análises físico-químicas: acidez titulável, percentual de proteína e gordura (Official..., 1997) e microbiológicas: Salmonella, coliformes a $30 / 35^{\circ} \mathrm{C}$, coliformes a $45^{\circ} \mathrm{C}$ e bolores e leveduras (Brasil, 2000a).

A contagem de Bifidobacterium spp. foi realizada um, sete, 15,30 e 40 dias após adição do probiótico em meio MRS (Himedia), semeadura pour plate, após incubação em anaerobiose (Gaspak, Difco), a $37^{\circ} \mathrm{C}$, por $72 \mathrm{~h}$.

Foram realizados testes para avaliar a aceitação (escala hedônica) e a intenção de consumo (escala de atitude) (Chaves e Sproesser, 1999). A equipe foi composta por 120 provadores, como determinado pelo método dos blocos completos para cinco amostras. O projeto foi aprovado previamente pelo Comitê de Ética e Pesquisa do Uni/BH (Protocolo nº 024/2007).

O delineamento experimental foi o de blocos ao acaso utilizando-se quatro espécies de bifidobactérias e a adição ou não de aroma. Para o tratamento estatístico dos dados, foi aplicada a análise de variância e, para a comparação de médias, empregou-se o teste Tukey $(\mathrm{P}<0,05)$. Os experimentos foram realizados em triplicata.

\section{RESULTADOS E DISCUSSÃO}

Na Tab. 1, apresentam-se os resultados provenientes de três experimentos quanto às análises físico-químicas e microbiológicas do leite de cabra cru e do leite de cabra tratado termicamente utilizado na fabricação do iogurte.

Tabela 1. Parâmetros físico-químicos e microbiológicos do leite de cabra cru e do leite de cabra tratado termicamente (média \pm desvio-padrão)

\begin{tabular}{|c|c|c|c|c|}
\hline & Leite de cabra cru & $\begin{array}{c}\text { Padrão } \\
\text { IN } 57\end{array}$ & $\begin{array}{l}\text { Leite de cabra } \\
\text { tratado } \\
\text { termicamente }\end{array}$ & $\begin{array}{l}\text { Padrão } \\
\text { IN } 57\end{array}$ \\
\hline $\begin{array}{l}\text { Densidade a } 15^{\circ} \mathrm{C} / 15^{\circ} \mathrm{C} \\
\text { pH } \\
\text { Acidez (g ácido } \\
\text { láctico/100g) } \\
\text { Gordura }(\% \mathrm{~m} / \mathrm{m}) \\
\text { Proteína }(\% \mathrm{~m} / \mathrm{m}) \\
\text { Lactose }(\% \mathrm{~m} / \mathrm{v}) \\
\text { Cinzas } \\
\text { Extrato seco total (\%) } \\
\text { Extrato seco } \\
\text { desengordurado (\% } \\
\text { m/m) } \\
\text { Contagem padrão em } \\
\text { placa } \\
\text { Coliformes a } 30 / 35^{\circ} \mathrm{C} \\
\text { Salmonella }\end{array}$ & $\begin{array}{c}1,0273 \pm 0,0003 \\
6,45 \pm 0,18 \\
0,16 \pm 0,02\end{array}$ & $\begin{array}{c}\text { 1,0280-1,0340 } \\
---- \\
0,13 \text { a } 0,18\end{array}$ & $\begin{array}{c}1,0301 \pm 0,0009 \\
6,41 \pm 0,28 \\
0,17 \pm 0,03 \\
2,97 \pm 0,55 \\
3,41 \pm 0,14 \\
3,54 \pm 0,06 \\
0,84 \pm 0,04 \\
11,21 \pm 1,10 \\
8,24 \pm 0,56 \\
\\
<10^{1} \\
<3 \\
\text { Ausência em } \\
\text { 25g de produto } \\
\text { analisado }\end{array}$ & $\begin{array}{c}\text { 1,0280-1,0340 } \\
\text {---- } \\
\text { 0,13 a 0,18 } \\
\text { Teor original } \\
\text { Mín 2,8 } \\
\text { Mín 4,3 } \\
\text { Mín 0,7 } \\
\text {---- } \\
\text { Mín 8,2 } \\
\\
\text { 5,00x10 } \\
\text { <3 } \\
\text { Ausência em } \\
\text { 25g de } \\
\text { produto } \\
\text { analisado }\end{array}$ \\
\hline
\end{tabular}

Mín: mínimo. 
Os valores médios encontrados para a densidade, o pH e a acidez do leite cru estão dentro dos padrões estabelecidos pela legislação brasileira (Brasil, 2000b). Pereira et al. (2005), ao analisarem o leite de cabra no estado da Paraíba, encontraram média de 1,0302 para densidade e de $0,16 \mathrm{~g}$ de ácido láctico/100g no produto para a acidez. Valores semelhantes foram encontrados por Fonseca (2006). No presente trabalho, apenas o valor encontrado para lactose, 3,54\%, esteve abaixo do recomendado pela legislação em vigor. Andrade (2000) encontrou 4,55\% de lactose no leite de cabra pasteurizado, valor acima do encontrado neste trabalho. Esse autor relatou que a lactose está sujeita a alterações durante o processamento do leite, envolvendo, principalmente, reações de Maillard durante o aquecimento e cristalização durante o congelamento. Ressalta-se, ainda, que a composição físico-química do leite de cabra é bastante variável em função de múltiplos fatores, tais como raça, período de lactação, clima, estação do ano, alimentação, idade do animal e produção de leite (Benedet e Carvalho, 1996).

A Instrução Normativa $n^{0} 37$ (Brasil, 2000b), que regulamenta a produção, identidade e qualidade do leite de cabra, cita o valor máximo de 5,00 x $10^{5} \mathrm{UFC} / \mathrm{mL}$ para a contagem padrão em placa; todas as amostras de leite cru estão muito próximas do padrão estabelecido. Valores médios de $1,58 \times 10^{5}$ foram encontrados por Fonseca (2006), e de $10^{6} \mathrm{UFC} / \mathrm{mL}$ por Kongo et al. (2006) e Cunha (2007). Os outros resultados microbiológicos visando à qualidade higiênicosanitária do leite de cabra tratado termicamente estavam em conformidade com a legislação em vigor.

Os resultados físico-químicos encontrados para a acidez $(0,64 \mathrm{~g}$ de ácido láctico/100 $\pm 0,02 \mathrm{~g})$ de todos os iogurtes de leite de cabra produzidos estavam de acordo com os parâmetros mínimos definidos na legislação brasileira para o produto. Os valores encontrados permitiram verificar que o tempo de fermentação foi suficiente para alcançar a acidez inicial desejável para iogurtes de, no mínimo, 0,6g de ácido láctico/100g, necessário para garantir a inibição do desenvolvimento de microrganismos patogênicos e deteriorantes que porventura sobrevivam ao tratamento térmico e que poderiam alterar o produto durante sua vida de prateleira (Brasil, 2000a). A tolerância de Bifidobacterium spp. à acidez é cepa específica. Lankaputhra e Shah (1995), ao estudarem a sobrevivência de nove cepas de Bifidobacterium spp. em condições ácidas ( $\mathrm{pH}$ 1,5-3,0), concluíram que $B$. longum e $B$. pseudolongum sobrevivem melhor em condições ácidas do que $B$. bifidum. Os resultados físico-químicos encontrados para o conteúdo em proteínas $(3,27 \% \pm 0,49)$ de todos os iogurtes de leite de cabra produzidos, adicionados ou não de Bifidobacterium spp. e adicionados ou não de aroma de morango, estavam de acordo com os parâmetros mínimos definidos na legislação brasileira para o produto (mínimo 2,9g de proteínas lácteas/100g de produto) (Brasil, 2000a) e não diferiram entre si ao longo do período de estocagem. Ao se analisar o valor encontrado para a proteína do leite de cabra e o valor encontrado para a proteína dos iogurtes, nenhuma interação foi observada $(\mathrm{P}>0,05)$.

Na Tab. 2, mostram-se os resultados encontrados para o teor de gordura nos iogurtes produzidos após 40 dias de fabricação. A análise estatística do percentual de gordura dos iogurtes mostrou não haver diferença entre a gordura do leite de cabra e a de todos os iogurtes preparados $(\mathrm{P}>0,05)$.

Tabela 2. Valores médios para o percentual de gordura dos diferentes iogurtes com 40 dias de produção

\begin{tabular}{lc}
\hline Tipo de iogurte & $\begin{array}{c}\text { Média } \pm \text { desvio- } \\
\text { padrão }\end{array}$ \\
\hline B. longum sem aroma & $2,60 \pm 0,17$ \\
B. longum com aroma & $2,77 \pm 0,06$ \\
B. breve sem aroma & $2,70 \pm 0,10$ \\
B. breve com aroma & $2,83 \pm 0,21$ \\
B. pseudolongum sem aroma & $2,73 \pm 0,06$ \\
B. pseudolongum com aroma & $2,75 \pm 0,14$ \\
B. bifidum sem aroma & $2,80 \pm 0,10$ \\
B. bifidum com aroma & $2,73 \pm 0,15$ \\
Iogurte sem aroma & $3,00 \pm 0,10$ \\
Iogurte com aroma & $2,80 \pm 0,10$ \\
\hline
\end{tabular}

As análises higiênico-sanitárias não demonstraram contaminação, e a contagem das células viáveis para bolores e leveduras permaneceram dentro dos padrões $\left(2 \times 10^{2} \mathrm{UFC} / \mathrm{g}\right)$ estabelecidos pela legislação em vigor (Brasil, 2000a). A avaliação estatística da contagem de bolores e leveduras mostrou não existir interação $(\mathrm{P}>0,05)$ entre as variáveis tempo e adição ou não de aroma para todos os iogurtes. 
A contagem de $S$. salivarius subsp. thermophilus durante a estocagem dos iogurtes até o $40^{\circ}$ dia não mostrou diferença significante nem interação entre as variáveis tempo e adição ou não de aroma $(\mathrm{P}>0,05)$. Neste estudo, não foi detectado o crescimento do microrganismo $L$. delbrueckii subsp. bulgaricus nas diluições utilizadas. Destaca-se que a legislação em vigor não estabelece a enumeração diferenciada para a cultura do iogurte. A manutenção do número de células viáveis de $S$. salivarius subsp. thermophilus atende aos valores estabelecidos pela legislação brasileira em vigor, mínimo $10^{7} \mathrm{UFC} / \mathrm{g}$ de bactérias lácteas totais viáveis no produto final, durante todo o prazo de validade (Brasil, 2000a). Além disso, o produto não foi afetado do ponto de vista tecnológico, uma vez que a aparência de coágulo uniforme, gel liso, brilhante, sem desprendimento de soro ou gases, foi mantida.

A proporção entre cocos e bacilos na cultura do iogurte é de 1:1 ou 2:1, podendo este equilíbrio ser quebrado com facilidade (Brandão, 1995). Assim, as indústrias fornecem culturas tradicionais de iogurtes com menor concentração de lactobacilos e maior concentração de cocos. A redução na contagem de lactobacilos no produto final contribui para diminuir a pós-acidificação do iogurte (Dave e Shah, 1997).

A contagem do número de células viáveis de Bifidobacterium spp. (B. longum, B. breve, $B$. pseudolongum $e$ B. bifidum) permaneceu entre $10^{6}$ e $10^{8} \mathrm{UFC} / \mathrm{mL}$ (Fig. 1 e 2 ). Considerando-se a adição ou não de aroma, a análise das variáveis tempo e aroma não mostrou diferença estatística. A contagem de Bifidobacterium spp. ao longo do tempo foi estatisticamente semelhante, demonstrando que nenhum Bifidobacterium apresentou um comportamento superior a outro. De acordo com Awaisheh et al. (2005), bactérias probióticas devem, após a ingestão, alcançar os intestinos em porcentagens elevadas para serem capazes de sobreviver, aderir às paredes intestinais, multiplicar-se e, talvez, exercer seus efeitos de promoção à saúde. Consequentemente, a viabilidade de espécies probióticas durante a armazenagem de leite fermentado é muito importante. Kongo et al. (2006), ao trabalharem com leite de cabra fermentado por $B$. animalis $e$ L. acidophilus, relataram que, durante a estocagem refrigerada do leite fermentado, ambas as espécies exibiram alta sobrevivência, com números viáveis em torno de $10^{7}$ UFC, constantes ao longo do experimento.

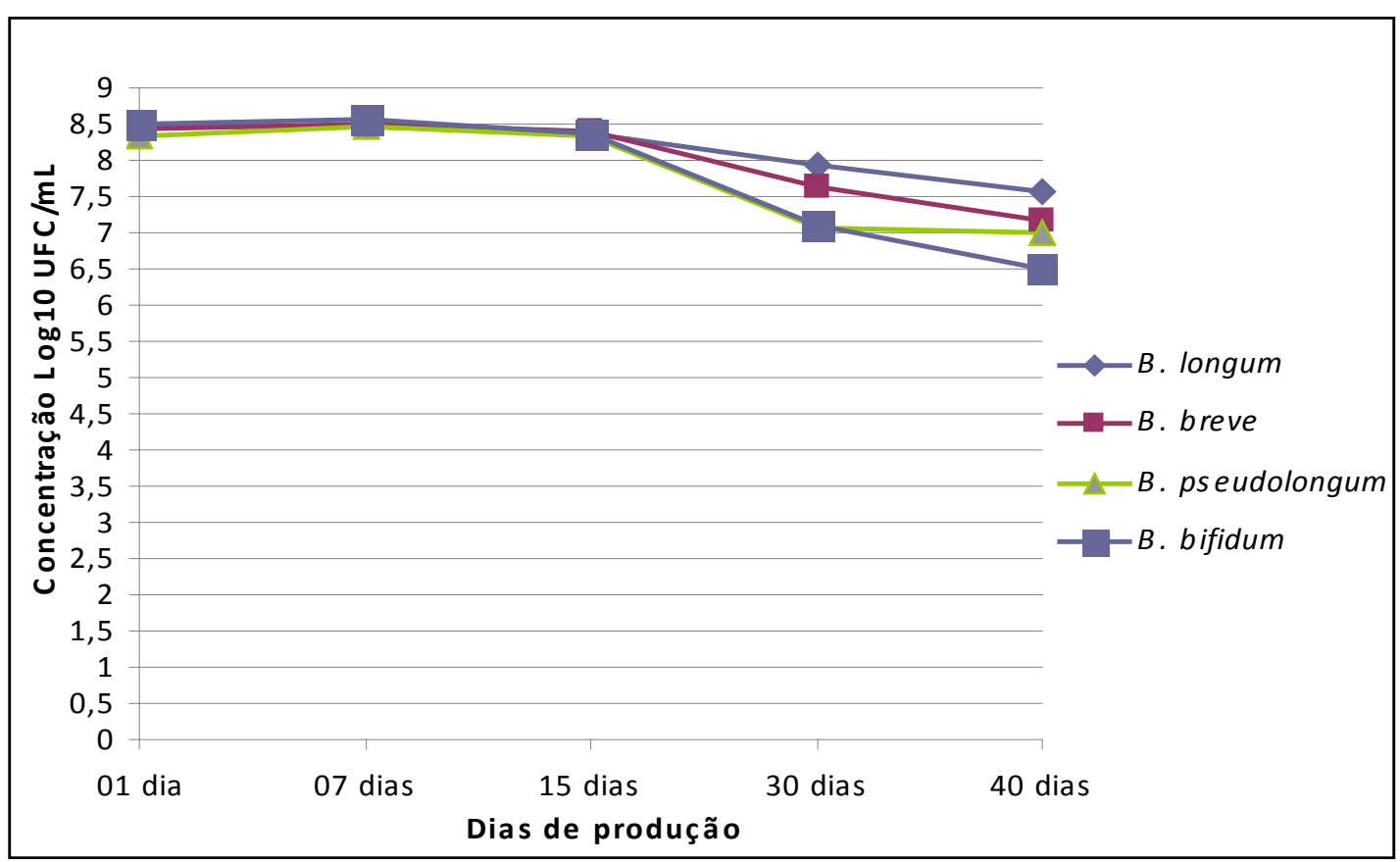

Figura 1. Média dos resultados encontrados para a contagem de Bifidobacterium spp. no iogurte de leite de cabra sem a adição de aroma de morango. 


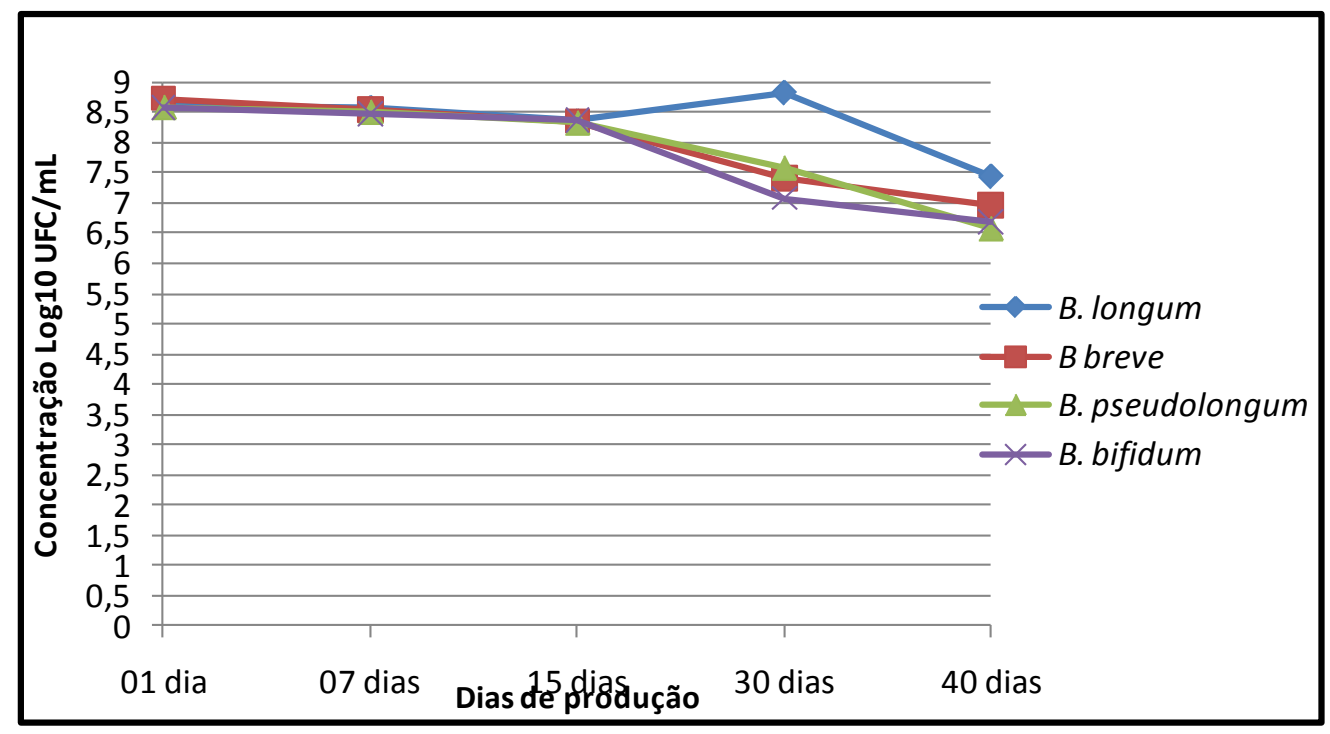

Figura 2. Média dos resultados encontrados para a contagem de Bifidobacterium spp. no iogurte de leite de cabra com a adição de aroma de morango.

Com relação a diferentes tipos de matéria-prima, Grosso e Fávaro-Trindade (2004), ao estudarem a estabilidade de $L$. acidophilus e B. lactis em leite de vaca acidificado, mostraram que a cultura tradicional do iogurte pareceu ter afetado negativamente a sobrevivência de $B$. lactis. Para Lourens-Hattingh e Viljoen (2001), a sobrevivência de bactérias probióticas em produtos lácteos fermentados depende de fatores como a interação entre as espécies presentes, as condições de cultura, a acidez final, o oxigênio dissolvido, o nível de inoculação e a temperatura de estocagem.

Nos testes das escalas hedônica e de atitude, as amostras de iogurtes adicionados ou não de Bifidobacterium spp. e adicionados de aroma de morango não apresentaram diferenças entre si para os atributos aparência, aroma, sabor, textura e para a intenção de compra.

\section{CONCLUSÕES}

O estudo mostrou ser possível a elaboração de iogurte de leite de cabra adicionado de Bifidobacterium spp. e de aroma de morango, permitindo desenvolver um produto probiótico ao longo de 40 dias de estocagem, sem interferir na identidade definida por características microbiológicas, físico-químicas e sensoriais do produto.

\section{AGRADECIMENTOS}

À Prof ${ }^{\mathrm{a}}$. Dr ${ }^{\mathrm{a}}$. Luciana Moreira Seara, pelo auxílio durante a análise estatística. À Prof ${ }^{\mathrm{a}}$. Dr ${ }^{\mathrm{a}}$. Cléia Batista Dias Ornellas, pela contribuição na análise sensorial. Ao Capril Jacomé, na pessoa do Sr. José Osvaldo de Souza Tavares, pela contribuição com os materiais utilizados, bem como pela assistência e compreensão.

\section{REFERÊNCIAS BIBLIOGRÁFICAS}

ANDRADE, P.V.D. Influência de processamentos térmicos sobre as características físico-químicas $e$ microbiológicas do leite de cabra, avaliado por diferentes métodos. 2000. 69f. Dissertação (Mestrado) - Escola de Veterinária, Universidade Federal de Minas Gerais, Belo Horizonte.

AWAISHEH, S.S.; HADDADIN, M.S.Y.; ROBINSON, R.K. Incorporation of selected nutraceuticals and probiotic bacteria into fermented milk. Int. Dairy J., v.15, p.1184-1190, 2005.

BENEDET, H.D.; CARVALHO, M.W. Caracterização de leite de cabra no estado de Santa Catarina, Brasil. Cienc. Tecnol. Alim., v.16, p.116119, 1996.

BRANDÃO, S.C.C. Tecnologia da produção industrial de iogurte. Leite Derivados, v.4, p.24-38, 1995.

BRASIL. Ministério da Agricultura, Pecuária e Abastecimento. Resolução $n^{\circ}$ 5, de 13 de novembro de 2000, Oficializa os padrões de identidade e qualidade (PIQ) de leites fermentados. Diário Oficial da União, Brasília, 27 de novembro de 2000a. 
BRASIL. Ministério da Agricultura, Pecuária e Abastecimento. Instrução Normativa ${ }^{\circ} 37$, de 31 de outubro de 2000. Aprova o regulamento técnico de identidade e qualidade de leite de cabra. Diário Oficial da União, Brasília, 8 de novembro de 2000b.

BRASIL. Ministério da Saúde. Agência Nacional de Vigilância Sanitária. Resolução RDC no 12, de 2 de janeiro de 2001. Aprova o Regulamento Técnico sobre padrões microbiológicos para alimentos. Diário Oficial da União, Brasília, 10 de janeiro de 2001.

CHAVES, J.B.P.; SPROESSER, R.L. Práticas de laboratório de análise sensorial de alimentos $e$ bebidas. Viçosa: UFV, 1999. 81p.

CORDEIRO, P.R.C. Opções de mercado do leite de cabra e derivados: perspectivas de desenvolvimento, industrialização e comercialização. In: ENCONTRO NACIONAL PARA O DESENVOLVIMENTO DA ESPÉCIE CAPRINA, 5., 1998, Botucatu. Anais... Botucatu: Faculdade de Medicina Veterinária e Zootecnia, 1998

COSTA, A.L. Leite caprino: um novo enfoque de pesquisa, 2003. Disponível em: $<$ http://www.cnpgl.embrapa.br/>. Acessado em: 20 jul. 2008.

CUNHA, F.L. Avaliação da qualidade microbiológica, físico-química e contagem de células somáticas em leite de cabra produzido na região de Nova Friburgo-RJ. Metodologia tradicional versus metodologia eletrônica. 2007. 74f. Dissertação (Mestrado) - Faculdade de Veterinária, Universidade Federal Fluminense, Niterói, RJ.

DAVE, R.I.; SHAH, N.P. Effect of cysteine on the viability of yoghurt and probiotic bacteria in yoghurt made with commercial starter cultures. Int. Dairy J., v.7, p.537-545, 1997.

FABIAN, E.; MAJCHRZAK, D.; DIEMINGER, B. et al. Influence of probiotic and conventional yoghurt on the status of vitamins B1, B2 and B6 in young healthy women. Ann. Nutr. Metabol., v.52, p.29-36, 2008.

FERREIRA, L.L.F.C.; MALTA, H.L.; CARELI, R.T. et al. Verificação da qualidade físico-química e microbiológica de alguns iogurtes vendidos na região de Viçosa. Rev. Inst. Lat. Cândido Tostes, v.56, p.152158, 2001.

FONSECA, C.R. Armazenamento do leite de cabra cru em diferentes temperaturas por diferentes períodos e influência nas qualidades microbiológica, físico-química e sensorial do produto pasteurizado. 2006. 87f. Dissertação (Mestrado) - Escola Superior de Agricultura Luiz de Queiroz, Universidade de São Paulo, Piracicaba, SP.
GROSSO, C.R.F.; FÁVARO-TRINDADE, C.S. Stability of free and immobilized Lactobacillus acidophilus and Bifidobacterium lactis in acidified milk and of immobilized B. lactis in yoghurt. Braz. J. Microbiol., v.35, p.151-156, 2004.

KONGO, J.M.; GOMES, A.M.; MALCATA, F.X. Manufacturing of fermented goat milk with a mixed starter culture of Bifidobacterium animalis and Lactobacillus acidophilus in a controlled bioreactor. Lett. Appl. Microbiol., v.42, p.595-599, 2006.

LANKAPUTHRA, W.E.V.; SHAH, N.P. Survival of Lactobacillus acidophilus and Bifidobacterium species in the presence of acid and bile salts. Cult. Dairy Prod. J., v.30, p.113-118, 1995

LEE, Y.K.; SALMINEN, S. The coming age of probiotics. Trends Food Sci. Technol., v.6, p.241-245, 1995.

LOURENS-HATTINGH, A.; VILJOEN, B.C. Yogurt as probiotic carrier food. Int. Dairy J., v.11, p.1-17, 2001.

MORAES, F.P.; COLLA, L.M. Alimentos funcionais e nutracêuticos: definições, legislação e benefícios à saúde. Rev. Eletr. Farm., v.3, p.109-122, 2006.

OFFICIAL methods of analysis. 16.ed. Arlington: AOAC, 1997.

O’SULLIVAN, M.G.; THORNTON, G.C. O`SULLIVAN, J.K. et al. Probiotic bacteria: myth or reality? Trends Food Sci. Technol., v.3, p.309, 1992.

PLANT, L.; CONWAY, P. Association of Lactobacillus spp. with Peyer'spatches in mice. Clin. Diagn. Lab. Immunol., v.8, p.320-324, 2001.

PEREIRA, R.A.G.; QUEIROGA, R.C.R.E.; VIANNA R.P.T. et al. Qualidade química e física do leite de cabra distribuído no Programa Social "Pacto Novo Cariri” no estado da Paraíba. Rev. Inst. Adolfo Lutz, v.64, p.205-211, 2005.

RIBEIRO E.L.A.; RIBEIRO, H.J.L.L. Uso terapêutico e nutritivo do leite de cabra. Sem. Cienc. Agr., v.22, p.229-235, 2001. 